\title{
Seroprevalence of COVID- 19 IgM and IgG antibodies among asymptomatic individuals in Khartoum State-2020
}

\begin{abstract}
Background: Seroprevalence detection of antibodies to severe acute respiratory syndromerelated coronavirus-2 (SARS-CoV-2) in apparent healthy individuals will be critical for the public health response to the coronavirus disease 2019 pandemic.

The aim of this study was to investigate the prevalence of IgM and IgG to covid-19 in Khartoum State.

Patients and methods: A cross-sectional retrospective laboratory-based investigation was conducted in Khartoum State 2020. Apparent healthy individuals without obvious respiratory conditions, and in order to obtain a travel license were exempted; however individuals who fulfilled the participation requirements were allowed to participate. After informed consent and fitting eligibility qualifications, a blood sample was taken from each respondent and used to identify SARS-CoV-2 IgM and IgG antibody tests in COVID-19 suspected informants using a snibe system model Maglumi 800. The Statistical Package for Social Sciences (SPSS) version 23 was used for statistical analysis in form of frequencies.

Results: In the state of Khartoum, a total of 1000 samples were collected from participants to determine seroprevalence of covid-19; of these, 224 were reactive and 776 were nonreactive. There were 158 reactive $\operatorname{IgG}$ and 66 reactive $\operatorname{IgM}$ within that reactive covid-19 patient.
\end{abstract}

Conclusion: There was a high prevalence of SARS-CoV-2 antibodies among asymptomatic respondents in Khartoum state.

Keywords: SARS-CoV-2, COVID-19, IgG, IgM, Khartoum, Sudan
Volume 9 Issue 3 - 2021

\author{
Magdi Babikir Omer,' Abduwahab Abakar \\ Fadil, ${ }^{2}$ Mohammed Ahmed Ibrahim Ahmed, ${ }^{3}$ \\ Nahla Ahmed Mohammed Abdelrahman, ${ }^{4}$ \\ Nassreldeen Khalid Abdelrahman Adam, ${ }^{5}$ \\ Marawa Ahmed Mohammed Abd Erahman, 6 \\ Rayan Hassan Sliman, ${ }^{2}$ Zeinab Ali Babeker ${ }^{2}$ \\ 'Assistant professor of Microbiology, Al Yarmouk University \\ College, Sudan \\ ${ }^{2}$ Faculty of Medical Laboratory Science, Al Yarmouk University \\ College, Sudan \\ ${ }^{3}$ Assistant professor of Microbiology, Faculty of Medicine, \\ Department of Microbiology, Nile Valley University, Sudan \\ ${ }^{4}$ Assistant professor of Biochemistry, Faculty of Medicine, \\ Department of Biochemistry, Nile Valley University, Sudan \\ ${ }^{5}$ Assistant professor of Epidemiology, Faculty of Medical \\ Laboratory Science, University of AI Fashir, Sudan \\ ${ }^{6}$ Assistant professor of Dermatology, Ministry of Health, Sudan
}

Correspondence: Dr. Mohammed Ahmed Ibrahim Ahmed, Assistant professor of Microbiology, Nile Valley University, Faculty of Medicine, Atbara, Sudan, Tel +2490I 22570655 , Email mohammedabukleewa@gmail.com

Received: May 10, 2021 | Published: May 26, 2021
Abbreviations: COVD-19, corona virus disease 2019; IgG, Immunoglobulin G; IgM, Immunoglobulin M; SARS-CoV-2, severe acute respiratory syndrome corona virus-2; RT-PCR, real time polymerase chain reaction

\section{Introduction}

Pneumonia cases were reported in a hospital in Wuhan, China, on December, 2019. ${ }^{1}$ After examining throat cultures from patients, the Chinese Center for Disease Control and Prevention stated that these infections were caused by a new form of beta-coronavirus. ${ }^{2}$ The coronavirus disease 2019 (COVID-19) caused by the severe acute respiratory syndrome coronavirus 2 (SARS-CoV-2) has soon emerged from an epidemic outbreak in Wuhan, $\mathrm{China}^{3}$ into a pandemic that has infected over a million people all over the globe. Attempts of social distancing and the pandemic's systemic effects concern billions of people. SARS-CoV-2 infects host human cells by binding to the angiotensin-converting enzyme 2 (ACE2) receptor, which is around $80 \%$ related to SARS-CoV. ${ }^{3}$ COVID-19 is primarily characterized as a respiratory tract infection, although new evidence shows that it should be considered a chronic infection affecting multiple systems, including the cardiovascular, respiratory, gastrointestinal, neurological, hematopoietic, and immune systems. Several reports have looked at the impact of COVID-19 on routine hematology variables in a range of countries. ${ }^{4-6}$
The precise mechanism of disease transmission is uncertain, but recent studies suggest that it is transmitted from person to person. Droplet-based and contact-based transmission routes are thought to be the most probable. ${ }^{7}$ Serologic investigations are performed on clinical samples such as blood, saliva, or even tears, in addition to molecular detection. Antibodies to SARS-CoV-2, such as IgA, IgM, and IgG, are defined using COVID-19 serologic assays. They're focused predominantly on enzyme-linked immunosorbent assays, which are less complicated than molecular studies. ${ }^{8}$ On December 31, 2019, the People's Republic of China announced a cluster of unidentified pneumonia cases to the World Health Organization (WHO). This outbreak was caused by a new coronavirus categorized as extreme acute respiratory syndrome coronavirus 2 (SARS-CoV-2) that was also accountable for the Corona Virus Disease 2019 (COVID-19). It has had an effect on over 200 countries and territories all over the globe. More than 26 million people have been infected and nearly 1000,000 have died as of mid-May 2020. The aim of this study was to determine the seroprevalence of COVID- 19 in Khartoum State.

\section{Patients and methods}

Study design, period\& area: During the months of October and December 2020, a cross-sectional retrospective laboratory analysis was conducted. This research was carried out in Khartoum. Sudan's administrative capital is located just south of the confluence of the 
Blue and White Niles. It is connected by bridge to the towns of Khartoum North and Omdurman, which together form Sudan's largest metropolitan area.

Study population, inclusion \& exclusion criteria: During the study period, inhabitants attend to Speed Medical Laboratories, a private pathologist-managed lab in order to travel outside Sudan. The report involved participants who came to examine Covid-19.Apparent healthy individuals of all age categories and both genders were involved.

Data collection tool, analysis \& sample size: Personal data were collected by direct interviewing questionnaires containing personal information, and laboratory investigations. For data analysis, version 23 of the statistical package for social sciences (SPSS) was used.

\section{Laboratory work}

Sample collection: After decontaminating the area with $70 \%$ alcohol, $5 \mathrm{ml}$ of venous blood was drawn from patients. The blood specimens were then left to clot for 30 minutes before being centrifuged at $3000 \mathrm{rpm}$ for 10 minutes. The serum was then extracted into plain containers and preserved at $-20 \mathrm{C}$ until examined.

Method: Using MAGLUMI ${ }^{\circledR}$ 2019-nCoV (SARS-CoV-2) IgM/IgG kits for detection of antibodies, The MAGLUMI 2019-nCoV IgG and IgM are two indirect CLIAs for assessment of IgG and IgM antibodies against SARS-CoV-2 in human serum or plasma samples, on the fully automated MAGLUMI analyzers (SNIBE -Shenzhen New Industries Biomedical Engineering Co.,Ltd, Shenzhen, China).

Ethical consideration: Before any specimens were collected, study respondents were informed of the research objectives and their permissions were obtained.

\section{Results}

This was a retrospective cross-sectional study using information from Speed Lab participants from October to December 2020 to estimate the prevalence of covid-19 antibodies in Khartoum, Sudan. The sample size was 1000 samples, with 224 of them being reactive to covid-19 and 776 being non-reactive (Table 1). Out of 224 reactive group, 158 were reactive to $\operatorname{IgG}$ and 66 were reactive to IgM (Table 2).

Table I Frequency of COVID-19 among study participants

\begin{tabular}{lll}
\hline Lab Result & Frequency (n) & Percent (\%) \\
\hline Reactive & 224 & 22.4 \\
Non-reactive & 776 & 77.6 \\
Total & 1000 & 100
\end{tabular}

Table 2 Frequency of IgG and IgM among study participants

\begin{tabular}{lll}
\hline Lab Result & Frequency (n) & Percent (\%) \\
\hline $\operatorname{lgG}$ & 158 & 15.8 \\
IgM & 66 & 6.6 \\
Non-reactive & 776 & 77.6 \\
Total & 1000 & 100
\end{tabular}

\section{Discussion}

In the light of the global public health crisis, serological monitoring may be a useful method for preventing COVID-19 transmission from person to person. ${ }^{9}$ The use of serological testing in the asymptomatic population or those with minor symptoms is important, since these people are not screened for viral RNA, masking the true rate of infection in the community. ${ }^{10}$ Since serologic tests can detect both current and past infections, we used them to estimate the prevalence of SARS-CoV-2 infection in asymptomatic people in Khartoum state. Our results indicate that $66(6.6 \%)$ of the eligible cases reported positive for IgM, while $158(15.8 \%)$ tested positive for IgG.

In terms of IgM results, the current study was almost equivalent to a study conducted in Spain, ${ }^{11}$ in which 578 samples $(6.1 \%)$ were positive for IgM. ${ }^{12}$ While a report conducted in $\mathrm{t}$ in Brazil contradicted this one. Their sample size was 3045 people, and 347 of them tested positive for IgM and 218 for IgG. This report also contradicts a study performed in Switzerland, ${ }^{13}$ which focused solely on IgG antibodies or SARS-CoV-2 (30), with findings based on 1335 people revealing a prevalence of $\operatorname{IgG}$ level of $9.7 \%$. Some important limitations shall be disclosed in this study. IgM and IgG. tests cannot be considered the serological gold standard for detection of COVID-19,the small sample size and the lack of a RT-PCR confirmatory test, therefore this study can only include an approximate representation of the COVID-19 epidemic's distribution in Sudan's capital. By the other hand apparent healthy individuals without symptoms of COVID-19 considered a major health concerns because those individuals were not be aware regarding prevention methods against transmission modalities of COVID-19 like social distance, face mask, disinfectants use, as well as other important preventive methods.

\section{Conclusion}

The study revealed a high prevalence of SARS-CoV-2 antibodies was found among Khartoum state resident among apparent healthy individuals.

\section{Acknowledgments}

Our best regards and thanks to the staff member of Speed medical laboratories and patients for their co-operation and acceptance to contribute this work.

\section{Conflicts of interest}

Authors declare that there is no conflict of interest.

\section{References}

1. Li Q, Ding X, Xia G, et al. Eosinopenia and elevated C-reactive protein facilitate triage of COVID-19 patients in fever clinic: A retrospective case-control study. E Clin Med. 2020;23:13-21.

2. Lu H, Stratton CW, Tang YW. Outbreak of pneumonia of unknown etiology in Wuhan, China: the mystery and the miracle. J Med Virol. 2020;92(4):401-402.

3. Zhu N, Zhang D, Wang W, et al. A novel coronavirus from patients with pneumonia in China, 2019. New Engl J Med. 2020;382(8):727-733.

4. Lippi G, Plebani M, Henry BM. Trombocytopenia is associated with severe coronavirus disease 2019 (COVID-19) infections: a meta-analysis. Clin Chim Acta. 2020;506:145-148.

5. Yang X, Yang Q, Wang Y, et al. Trombocytopenia and its association with mortality in patients with COVID-19. J Thromb Haemost. 2020;18(6):1469-1472. 
6. Henry BM, Santos de Oliveira MH, Benoit S, et al. Hematologic, biochemical and immune biomarker abnormalities associated with severe illness and mortality in coronavirus disease 2019 (COVID-19): a metaanalysis. Clin Chem Lab Med. 2020;58 (7):1021-1028.

7. Centers for Disease Control and Prevention. First travel-related Case of 2019 Novel Coronavirus Detected in United States. U.S Department of Health \& Human Services; 2020.

8. Cheng MP, Yansouni CP, Basta NE, et al. Serodiagnostics for Severe Acute Respiratory Syndrome-Related Coronavirus-2. Annals of Internal Medicine. 2020;173(6):450-460.

9. Toulis P. Estimation of COVID-19 Prevalence from serology tests: A Partial Identification Approach. J Econom. 2021;220(1):193-213.
10. Infantino M, Damiani A, Gobbi FL, et al. Serological Assays for SARSCoV-2 Infectious Disease: Benefits, Limitations and Perspectives. Isr Med Assoc J. 2020;22(4):203-210.

11. Garcia-Basteiro AL, Moncunill G, Tortajada M, et al. Seroprevalence of antibodies against SARS-CoV-2 among health care workers in a largeSpanish reference hospital. Nat Commun. 2020;11(1):3500.

12. Borges LP, Martins AF, Melo MS, et al. Seroprevalence of SARS-CoV-2 IgM and IgG antibodies in an asymptomatic population in Sergipe, Brazil. Rev Panam Salud Publica. 2020;44:e108.

13. Stringhini S, Wisniak A, Piumatti G, et al. Repeated seroprevalence of anti 1 -SARS-CoV-2 IgG antibodies in a population- based sample. medRxiv; 2020. 